\title{
Scrum Team Competence Based on Knowledge, Skills, Attitude in Global Software Development
}

\author{
Anita HIDAYATI ${ }^{1}$, Eko K. BUDIARDJO2*,Betty PURWANDARI ${ }^{3}$ \\ ${ }^{1}$ Ph.D. student at Faculty of Computer Science, Universitas Indonesia, Full-time lecturer at Department of Computer \\ Informatics Engineering, Jakarta State Polytechnic, Email: anita.hidayati@ui.ac.id \\ 2Professor at Faculty of Computer Science, Universitas Indonesia, Email: eko@cs.ui.ac.id \\ ${ }^{3}$ Ph.D, full-time lecturer at Faculty of Computer Science, Universitas Indonesia, Email: bettyp@cs.ui.ac.id \\ * Corresponding Author
}

Received: 30.06.2021 Accepted: 24.08.2021 Published: 08.10.2021 DOI: 1 10.47750/QAS/22.184.11

\begin{abstract}
Global Software Development (GSD) and Scrum are two pivotal tools in software engineering, which meet the needs of global economics in dealing with various disruptions, such as physical distancing due to the COVID-19 pandemic. This research focuses on Scrum with its three roles: Product Owner, Scrum Master and Development Team. They require a distinct set of competencies, including Knowledge, Skills, and Attitude (KSA). Therefore, this study aims to develop a list of Scrum team competence based on KSA in GSD. The authors conducted a comprehensive literature review to create the list. Then, it was followed by in-depth interviews with nine experts involving practitioners and academics having experience in Scrum, GSD, and educational psychology for validation. This study proposes a compilation of KSA-based competencies for all roles of the Scrum team. Each competency has been grouped and given a level based on Bloom's taxonomy. The research findings can be the basis for successful competency development for the Scrum team.
\end{abstract}

Keywords: global software development; Scrum Team; competence; knowledge; skill; attitude, bloom taxonomy.

\section{Introduction}

Global Software Development (GSD) is in great demand by IT companies in developing their software. Some reasons for implementing GSD are cost savings, ease of getting a skilled workforce, increased system development time, flexibility, and closeness to the local market (Ebert et al., 2016). The biggest reason is cost savings, especially the salaries of software engineers (Sievi-korte et al., 2018). Moreover, implementing GSD can also improve the quality of the system development time. Various time zones in the software engineers' residence allow system development to execute 24 hours (Kroll et al., 2018). Besides, GSD has provided software development continuity solutions as the COVID-19 pandemic necessitates governments to enforce physical distancing (Garro-Abarca et al., 2021).

GSD has three distances from offering many benefits: Temporal, Geographical, Socio-cultural (Casado-Lumbreras et al., 2014) that affect three challenges: Coordination, Control, Communication (Vallon et al., 2018). This study focused on Scrum as a prospective and popular methodology to harness the advantages of GSD (Vallon et al., 2018). It took particular competencies from the Scrum team in the GSD environment, as the human factor is at the core of Scrum methodology (Ibrahim et al., 2016). A Scrum team that has good competence will be successful in working on GSD projects. This study aims to develop a list of Scrum team competence based on KSA in GSD. The authors conducted a comprehensive literature review to create the list.

\section{Previous Works}

The 14th Annual State of Agile Report in 2020 mentions that Scrum is the most widely applied methodology. There is increasing interest in using Scrum practices in GSD projects originating from intra-organizational and multi-national companies (Vallon et al., 2018). Scrum requires some adjustments to answer the challenges (Paasivaara et al., 2009).

Mapping was conducted and is presented in Table 1 to explore threats and opportunities in implementing Scrum GSD. The snowball method was used to gather papers that discussed the application of Scrum in GSD and discover thirteen articles with a period of 2009-2020. Over the last five years, some documents were still referred to because they made significant contributions and came from trusted journals and conferences.

Table 1 is a correlation matrix between three distances and three challenges, a development from previous research (Mistrík et al., 2014). Each comparison can have a different number of opportunities $(+)$, challenges $(-)$, and competencies $\left(^{*}\right)$. For example, the relationship between communication with temporal and socio-cultural distance produces one challenge and one chance. Meanwhile, when connected with Geographical Distance, it creates one challenge and two opportunities. Table 1 shows that a Scrum team with its competencies can overcome the challenges and opportunities of Scrum practices in the GSD environment (Motawi et al., 2018). 


\section{GENERAL MANAGEMENT}

\begin{tabular}{|c|c|c|c|}
\hline & Temporal Distance & Geographical Distance & Socio-Cultural Distance \\
\hline 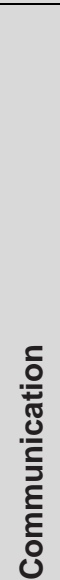 & 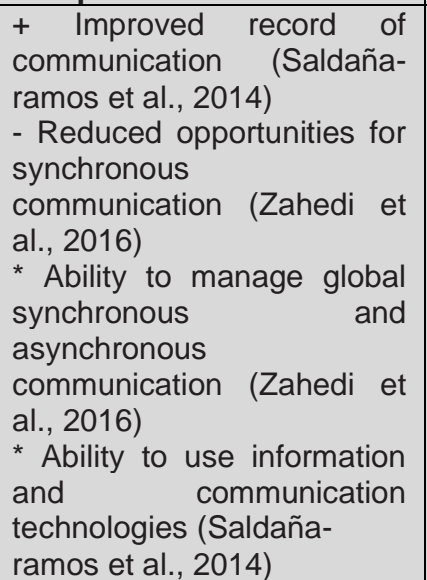 & $\begin{array}{l}\text { + Closer proximity to the market (Peters } \\
\text { et al., 2015) } \\
\text { + Access to remote skilled workforces } \\
\text { (Saldaña-ramos et al., 2014) } \\
\text { - Face to face meetings are difficult } \\
\text { (Holtkamp et al., 2015) } \\
\text { *Ability to effectively communicate using } \\
\text { common terminology and } \\
\text { language (Peters et al., 2015) } \\
\text { * Ability to identify competence and skill } \\
\text { of teamwork (Saldaña-ramos et al., } \\
\text { 2014) } \\
\text { * Understanding of importance and } \\
\text { limitations of various information } \\
\text { sources (Holtkamp et al., 2015) }\end{array}$ & $\begin{array}{l}+ \text { Innovation and sharing of best } \\
\text { practices (Khan \& Khan, 2017) } \\
\text { - Cultural misunderstandings (Holtkamp } \\
\text { et al., 2015) } \\
\text { * Ability to share knowledge and } \\
\text { information and have initiative (Khan \& } \\
\text { Khan, 2017) } \\
\text { * Understanding of the influences and } \\
\text { implications of culture and other } \\
\text { personalities in work life, ability to } \\
\text { communicate sensitively (Holtkamp et } \\
\text { al., 2015) }\end{array}$ \\
\hline 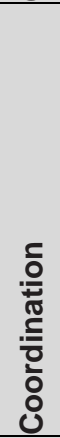 & $\begin{array}{l}\text { + Coordination needs can be } \\
\text { minimalised (Saldaña- } \\
\text { ramos et al., 2014) } \\
-\quad \text { Typically, increased } \\
\text { coordination costs (Saldaña- } \\
\text { ramos et al., 2014) } \\
\text { * Ability to use advanced } \\
\text { techniques for distributed } \\
\text { communications (Saldaña- } \\
\text { ramos et al., 2014) }\end{array}$ & $\begin{array}{l}+ \text { More flexible coordination planning } \\
\text { (Jim et al., 2014) } \\
\text { - Reduced informal contact can lead to a } \\
\text { lack of critical task awareness (Peters et } \\
\text { al., 2015) } \\
\text { * Ability to communicate with a } \\
\text { distributed team (Jim et al., 2014) } \\
\text { * Ability to communicate informally and } \\
\text { improvisation skills (Peters et al., 2015) }\end{array}$ & $\begin{array}{l}\text { + Greater learning and richer skill set } \\
\text { (Holtkamp et al., 2015) } \\
\text { - Inconsistent work practices can } \\
\text { impinge on effective coordination (Jim } \\
\text { et al., 2014) } \\
\text { - Reduced cooperation arising from a } \\
\text { misunderstanding (Peters et al., 2015) } \\
\text { * Ability to use other people's } \\
\text { knowledge and expertise (Holtkamp et } \\
\text { al., 2015) } \\
\text { * Skills to gain the team's trust and } \\
\text { confidence (Peters et al., 2015) }\end{array}$ \\
\hline $\begin{array}{l}\overline{0} \\
\text { 은 } \\
\text { 응 }\end{array}$ & $\begin{array}{l}\text { + Time zone effectiveness } \\
\text { can be utilized for gaining } \\
\text { efficient } 24 \times 7 \text { working } \\
\text { (Tuffley, 2012) } \\
\text { - Management of project } \\
\text { artefact may be subject to } \\
\text { delays (Monasor, Vizcaíno, } \\
\text { \& Piattini, 2010) } \\
\text { * Leadership skills and time } \\
\text { management skills (Tuffley, } \\
2012 \text { ) } \\
\text { * Ability to use knowledge } \\
\text { and document management } \\
\text { and control version tools } \\
\text { (Monasor, Vizcaíno, \& } \\
\text { Piattini, 2010) }\end{array}$ & $\begin{array}{l}\text { + Communication channels can leave an } \\
\text { audit trail (Monasor, Vizcaíno, Piattini, et } \\
\text { al., 2010) } \\
\text { - Difficult to convey vision and strategy } \\
\text { (Alsanad et al., 2019) } \\
\text { - Perceived threat from low-cost training } \\
\text { rivals (Beecham et al., 2014) } \\
\text { * Knowledge of data, tools, methods, } \\
\text { and processes in a distributed project } \\
\text { (Monasor, Vizcaíno, Piattini, et al., 2010) } \\
\text { *Ability to adapt and adjust plans, goals, } \\
\text { and strategies (Holtkamp et al., 2015) } \\
\text { * Ability to create and manage online } \\
\text { training (Gheni et al., 2019) }\end{array}$ & $\begin{array}{l}+ \text { Proactiveness inherent in certain } \\
\text { cultures (Holtkamp et al., 2015) } \\
\text { - Different perceptions of authority can } \\
\text { undermine morale (Moe et al., 2010) } \\
\text { - Managers must adapt to local } \\
\text { regulations (Peters et al., 2015) } \\
\text { * Ability to manage diversity within the } \\
\text { team, allowing everyone to contribute } \\
\text { and participate (Holtkamp et al., 2015) } \\
\text { * Positive attitude and motivation } \\
\text { capacity (Moe et al., 2010) } \\
\text { *Managing ambiguity and uncertainty } \\
\text { (Peters et al., 2015) }\end{array}$ \\
\hline
\end{tabular}

Table 1: Scrum GSD opportunities and challenges

Additional literature studies were conducted to enrich the references. This research used the snowball method and discovered a total of 18 references. The results of literature studies were used to develop the list of competencies in Table 1. Competencies were identified for each role in the Scrum team, namely Product Owner, Scrum Master, dan Development Team. In the next step, we used Bloom's Taxonomy as a reference to classify competencies into KSA and assess the acquired level. Activities in GSD indirectly link the development of KSA with the Scrum Team.

\section{KSA Based Competency}

Competence is a demonstrated ability to apply KSA to achieve observed results (European Committee for Standardization (CEN), 2014). Review capabilities from an individual perspective can use KSA-based competencies (Holtkamp et al., 2015). Competence refers to the characteristics of an individual that makes up superior performance. Construct educational objectives focusing on curriculum development used Bloom's taxonomy (Ching \& Da Silva, 2017).

Bloom's taxonomy is a hierarchical structure that identifies skills ranging from low to high levels. In order to reach a higher level, the lower level must be completed first. Within this conceptual framework, Bloom's Taxonomy refers to taxonomies for educational purposes and is categorized into three domains of intellectual behavior: cognitive $(K)$, affective $(A)$, and psychomotor (S). Table 2 shows Bloom's taxonomy of KSA and its level. The Preparation of KSA used these verbs and levels. The use of Bloom's taxonomy has so far focused on $\mathrm{K}$ rather than S or A (Adams, 2015). The contribution of this research is to discuss the components of KSA thoroughly. 


\begin{tabular}{|l|l|l|l|}
\hline Level & Knowledge & Skills & Attitude \\
\hline 1 & Remember & Perception/awareness & Receiving \\
\hline 2 & Understand & Set & Responding \\
\hline 3 & Application & Guided response & Valuing \\
\hline 4 & Analysis & Mechanism & Organisation \\
\hline 5 & Evaluation & Complex overt response & Characterization \\
\hline 6 & Creation & Adaptation & - \\
\hline 7 & - & Origination & - \\
\hline
\end{tabular}

Table 2: Bloom's taxonomy

\section{Validation}

This research conducted in-depth interviews involving Scrum, GSD, and educational psychology experts to validate the compiled competencies. Their data are in Table 3. The two experts are currently domiciled in the Netherlands and worked for companies $A$ and $G$, while others are from Indonesia.
Interviews were conducted online via a zoom meeting with 1-2 hours for each expert to sought input and suggestions from Scrum GSD experts regarding the suitability of compiled competencies with practice in the field. Several weeks earlier, the draft list of competencies was sent to them. When conducting the interview, the experts have understood the material and are ready with their thoughts.

\begin{tabular}{|l|l|l|l|}
\hline Company & Business Type & Position & Expertise \\
\hline A & e-commerce & Senior Software Engineer & Scrum, GSD \\
\hline B & IT Services, software solution & Chief Executive Officer & Scrum, GSD \\
\hline C & Online coding learning platform & Co-Founder & Scrum \\
\hline D & Consulting, research \& legal Services & Chief Executive Officer & Scrum, GSD \\
\hline E & Digital commerce platform & Chief Executive Officer & Scrum \\
\hline F & Transaction banking platform provider & $\begin{array}{l}\text { Head of Quality Assurance- } \\
\text { Product Development }\end{array}$ & Scrum, GSD \\
\hline G & Software and technology services & Data Architect & Scrum, GSD \\
\hline H & Vocational public university & Educational Psychology Lecturer & Competency \\
\hline I & Public university & Educational Psychology Lecturer & Competency \\
\hline
\end{tabular}

Table 3: Expert's data

The in-depth interview consisted of two stages. The first stage involved seven Scrum and GSD experts. These interviews aimed to confirm the suitability of each competency with its application in industrial practices. In addition, there was also an examination of the appropriateness of competency groupings in the roles of Scrum Master, Product Owner, and Development Team. There were discussions for each competency in detail.

After making improvements according to the experts' input, the author tried to group the competencies into KSA and score the level. The second stage involves two educational psychology experts aiming to validate grouping and level from academic perspectives. The recording results were analyzed with content analysis using NVivo software tools to obtain input points for improving the KSA competency structure.

\section{Findings}

The compiled competency list has obtained a great deal of input from the first stage of in-depth interviews with Scrum and GSD experts. The experts considered that some competencies should be removed, and new competencies should be added to the list. Assessed from the grouping of competencies to a role of the Scrum team, several competencies do not fit into the three roles of the Scrum team. So, there are additions or deletions of competencies from these roles. Improvements were made based on these inputs.

\section{Discussion}

This study's findings reinforce previous studies' opinions that many difficulties arise when the Scrum team works in a GSD environment (Noll et al., 2016). The Scrum teams must master more complex competencies to implement the modified Scrum practices successfully. The developed competencies greatly help them prepare to face the distances and challenges of modified Scrum practice in a GSD environment.

With the expert's input on the compiled competencies, there were some improvements on several aspects of competencies. The first improvement was the addition and deletion of competencies based on suggestions from the experts. The second was revisions of the discrepancies in the Scrum team's role of ownership of competency. It relates to a competency that should be included or removed from one of the Scrum team roles. In other words, several competencies were not in the right places; for example, the transfer of competency from Development Team to Product Owner, from Scrum Master to Development Team, from Scrum Master to Product Owner, and other transfers.

The third was on the sentence structure to suit the context of the intended competence. Attitude (A) was added to some competencies by providing words that explicitly show Attitude $(A)$ in the sentence. Last, adjust the competency grouping, the verb, and leveling by refers to Bloom's taxonomy. Some competencies are not according to the level; for example, they should be at level 6 but given level 5 . Also, some verbs are not according to their level, so they must be replaced. A small part of the composition of competence can be seen in Table 4-Column $\mathrm{K}$ for Knowledge, S for Skills, and A for Attitude. The detailed competence developed in this work is available at http://rse.cs.ui.ac.id/?open=gsd/ index. 
Competencies for Development Team, Scrum Master, Product Owner

Ability to discuss how to manage the technical risks be effective in the empirical process (Scrum.org, 2020)

Ability to use clear and fluent writing and conversation in a foreign language to communicate with teams with different cultures and personalities (Srivastava \& Jain, 2017)

Ability to describe the concept of GSD and the application of Scrum in GSD (Hossain \& Babar, 2009)

Competencies of Development Team and Scrum Master

Ability to associate Agile values and principles with practical Scrum in GSD context (Faniran et al., 2017)

Competencies of Scrum Master and Product Owner

Ability to cope with conflicts with geographically dispersed stakeholders (Bass, 2013)(Noll \& Butterfield, 2016)

Ability to explore ways of implementing practices to make risks transparent (Arumugam \& Kaliamourthy, 2017)

Competencies of Development Team and Product Owner

Ability to facilitate re-platforming and security considerations with technology leadership (Noll \& Butterfield, 2016)

Ability to manage and approve release planning and schedule (Majeed, 2012)

Habitually practicing, which makes the work and collaboration more agile (Faniran et al., 2017)

Development Team Competencies

Ability to adapt working hours to get efficiency from the Follow the Sun concept (Bass, 2015)(Maria \& Vilardell,

2016)(Hossain \& Babar, 2009)

Ability to assess Scrum practices and products from various cultural perspectives (Maria \& Vilardell, 2016)

Ability to make incremental products to produce value (Scrum.org, 2020)

Ability to adapt to different cultures and overcome interpersonal conflicts (Zahedi \& Ali Babar, 2016)

Ability to form cooperation and coordination with Development Teams in other locations (Bass, 2013)(Majeed, 2012)

\section{Scrum Master Competencies}

Ability to support Development Team and Product Owner tailored to the distributed work allocation (Srivastava \&

Jain, 2017)

Ability to make organizations understand and apply Agile principles in GSD (Beecham et al., 2014)

Ability to form cooperation and coordination with Scrum Masters in other locations (Bass, 2013)(Majeed, 2012)(Bass, 2015)(Maria \& Vilardell, 2016)

Ability to facilitate the combination of distributed and centralized Scrum team (Bass, 2014)(Maria \& Vilardell, 2016)

Ability to direct, support, supervise, and maintain the development process by providing the information needed by distributed teams (Bass, 2014)(Hossain \& Babar, 2009)

\section{Product Owner Competencies}

Ability to direct the conflict within a team so that each member feels challenged, encouraged, and motivated (Bass, 2015)(Noll \& Butterfield, 2016)

Capability guarantees what many Scrum GSD teams need (Maria \& Vilardell, 2016)

Ability to review collaboration strategies with other Product Owners (Maria \& Vilardell, 2016)

Ability to make stakeholders or customers involved and update at any time (Maria \& Vilardell, 2016)

Ability to facilitate communication between customer and distributed Development Team (Srivastava \& Jain, 2017)

Table 4: Competence-based KSA for Scrum GSD team

The grouping was done because there are many slices of competence from the Scrum team's three roles. The first is the competence possessed by all roles. Next is the competence possessed by two roles: Development Team with Scrum Master, Scrum Master with Product Owner, and Development Team with Product Owner. The rest are competencies owned by each role.

Developing an educational process for increasing competence by compiling courses can use data from Table 4. The steps are designing instructional activities and assessment criteria for competencies as learning objectives. Planned activities can be in the form of discussion, oral presentation, case studies, simulation of actual situations with games, or group dynamics in developing software projects (Ching \& Da Silva, 2017)(Mahnič, 2015). One example of implementing Scrum teaching with practical team-based project work is using Scrum protocols and artifacts in previous research (Poženel \& Mahniè, 2016).

The common assessment method is in the form of questions. Examples of question models can refer to previous studies (Ching \& Da Silva, 2017)(Kim et al., 2012). One example of a Scrum team competency assessment is the open assessment available at www.scrum.org. Some questions utilize multiplechoice models: choose one of two or many choices and choose two or more of the many options provided.

These competencies are beneficial for formal and informal education. Higher education can incorporate them into teaching materials and curricula. For the training institutions, they could be references in preparing training programs and certification. The expected output is a Scrum team whose members are competent so they can work successfully in GSD.

\section{Conclusions And Future Works}

After a comprehensive literature review, in-depth interviews, and data processing using content analysis, the Authors compiled a KSA-based competency with its corresponding levels. Each Scrum team's roles, namely, Product Owner, Scrum Master, and Development Team, have their own KSA set. Not all competencies have a complete Knowledge (K), Skills (S) Attitude (A) component. Some competencies have one part, namely, $K$ or $A$ only. Others have two parts, namely, $K$ with $A, K$ with $\mathrm{S}$, or $\mathrm{S}$ with $\mathrm{A}$.

There are competencies that all Scrum team roles must have because they are the nature of Scrum and GSD. Several slices of competencies show the close collaboration of roles in the Scrum team, which is cross-functional (George et al., 2018). Particular competencies only have one role, which indicates the division of tasks in a self-managed Scrum team.

The research significantly contributes to forming the basis for 
developing instructional activities and assessment criteria. This study provides an enriching reference for future studies that focus on GSD, competence, and KSA.

The authors will conduct validation involving stakeholders from the company and the GSD Scrum team, training institutions, professional associations, and government representatives for further research. The next project will develop a maturity model to enhance the competence of the Scrum team.

\section{Acknowledgments}

This research was supported by a PDUPT grant at the University of Indonesia (8/E1/KP. PTNBH/2020 NKB115/UN2.RST/HKP.05.00/ 2020 addendum NKB2714/UN2.RST/ HKP.05.00/2020), funded by the Ministry of Research, Technology and Higher Education of the Republic of Indonesia.

\section{References}

[1] Adams, N. E. (2015). Bloom's taxonomy of cognitive learning objectives. Journal of the Medical Library Association, Vol. 103 No. 3, 152-153.

[2] Alsanad, A. A., Chikh, A., \& Mirza, A. (2019). A Domain Ontology for Software Requirements Change Management in Global Software Development Environment. IEEE Access, Vol. 7, 49352-49361.

[3] Arumugam, C., \& Kaliamourthy, B. (2017). Global Software Development: A design to measure risk of global practitioners. 2016 International Conference on Computing, Analytics and Security Trends, CAST 2016, 590-593.

[4] Bass, J. M. (2015). How product owner teams scale agile methods to large distributed enterprises. Empirical Software Engineering, Vol. 20 No. 6, 1525-1557.

[5] Bass, J. M. (2013). Agile Method Tailoring in Distributed Enterprises: Product Owner Teams. IEEE 8th International Conference on Global Software Engineering, 154-163.

[6] Bass, J. M. (2014). Scrum Master Activities : Process Tailoring in Large Enterprise Projects. IEEE 9th International Conference on Global Software Engineering, 6-15.

[7] Beecham, S., Noll, J., \& Richardson, I. (2014). Using Agile practices to solve Global Software Development problems - A Case Study. 2014 IEEE International Conference on Global Software Engineeering Workshops, 5-10.

[8] Casado-Lumbreras, C., Colomo-Palacios, R., Francisca, N., \& Misra, S. (2014). Software Development Outsourcing: Challenges and Opportunities in Nigeria. Journal of Global Information Technology, Vol. $17,267-282$.

[9] Ching, H. Y., \& Da Silva, E. C. (2017). The use of Bloom's Taxonomy to develop Competences in Students of a Business Undergrad Course. Journal of International Business Education, Vol. 1, 107-126.

[10] Ebert, C., Kuhrmann, M., \& Prikladnicki, R. (2016). Global software engineering: Evolution and trends. Proceedings - 11th IEEE International Conference on Global Software Engineering, ICGSE 2016, 144-153.

[11] Faniran, V. T., Badru, A., \& Ajayi, N. (2017). Adopting Scrum as an Agile approach in distributed software development: A review of literature. 1st International Conference on Next Generation Computing Applications, NextComp 2017, 36-40.

[12] Garro-Abarca, V., Palos-Sanchez, P., \& Aguayo-Camacho, M. (2021). Virtual Teams in Times of Pandemic: Factors That Influence Performance. Frontiers in Psychology, Vol. 12 (February), 1-14.

[13] George, J. F., Scheibe, K., Townsend, A. M., \& Mennecke, B. (2018). The amorphous nature of agile: no one size fits all. Journal of Systems and Information Technology, Vol. 20 No. 2, 241-260.
[14] Gheni, A. Y., Jusoh, Y. Y., Jabbar, M. A., Ali, N. M., Shanmugam, M., \& Yousif, H. A. (2019). Measuring the performance of the virtual teams in global software development projects. Journal of Information Technology Management, Vol. 11 No. 1, 43-59.

[15] Holtkamp, P., Lau, I., \& Pawlowski, J. M. (2015). How software development competences change in global setting-an explorative study. Journal of Software: Evolution and Process, Vol. 27, 50-72.

[16] Hossain, E., \& Babar, M. A. (2009). Using Scrum in Global Software Development: A Systematic Literature Review. International Conference on Global Software Engineering, 175184.

[17] Ibrahim, Y., Qumer, A., \& Al-ani, A. (2016). Empirical studies of geographically distributed agile development communication challenges: A systematic review. Information \& Management, Vol. 53, 22-37.

[18] Jim, M., Supervisors, M., Vizca, A., \& Velthuis, M. P. (2014). A framework for interaction training in Global Software Development.

[19] Khan, S. U., \& Khan, A. W. (2017). Critical challenges in managing offshore software development outsourcing contract from vendors ' perspectives. IET Software, Vol. 11, 1-11.

[20] Kim, M. K., Patel, R. A., Uchizono, J. A., \& Beck, L. (2012). Incorporation of Bloom's taxonomy into multiple-choice examination questions for a pharmacotherapeutics course. American Journal of Pharmaceutical Education, Vol. 76 No. 6.

[21] Kroll, J., Richardson, I., Prikladnicki, R., \& Audy, J. L. N. (2018). Empirical evidence in follow the Sun software development: A systematic mapping study. Information and Software Technology, Vol. 93, 30-44.

[22] Mahnič, V. (2015). Scrum in software engineering courses: An outline of the literature. Global Journal of Engineering Education, Vol. 17 No. 2, 77-83.

[23] Majeed, H. (2012). Issues and Challenges in Scrum Implementation. International Journal of Scientific \& Engineering Research, Vol. 3 No. 8, 1-4.Maria, R., \& Vilardell, F. (2016). Scaling Agile Scrum Software Development. 2016 IEEE 11th International Conference on Global Software Engineering (ICGSE), 84-88.

[24] Mistrík, I., Beecham, S., Richardson, I., \& Avritzer, A. (2014). Knowledge engineering in global software development environments. Expert Systems, Vol. 31 No. 3, 232-233.

[25] Moe, N. B., Dingsøyr, T., \& Dybå, T. (2010). A teamwork model for understanding an agile team: A case study of a Scrum project. Information and Software Technology, Vol. 52 No. 5, 480-491.

[26] Monasor, M. J., Vizcaíno, A., \& Piattini, M. (2010). A Tool for Training Students and Engineers. Global Software Development Practices. CRIWG 2010, 169-184.

[27] Monasor, M. J., Vizcaíno, A., Piattini, M., Caballero, I., Universidad, P. De, Real, C., Vizcaino, A., \& Piattini, M. (2010). Preparing Students and Engineers for Global Software Development: A Systematic Review. International Conference on Global Software Engineering, 177-186. Motawi, T. A. A., Kamel, A., \& Hassan, H. (2018). A Framework for Agile Global Software Development: The Case of an International Software Company in Egypt. Indian Journal of Science and Technology, Vol. 11 No. $25,1-14$.

[28] Noll, J., Beecham, S., Richardson, I., \& Canna, C. N. (2016). A Global Teaming Model for Global Software Development Governance: A Case Study. 2016 IEEE 11th International Conference on Global Software Engineering (ICGSE), 179-188.

[29] Noll, J., \& Butterfield, A. (2016). Teaching Global Software Development through Game Design. 11th International Conference on Global Software Engineering Workshops, 55-60.

[30] Paasivaara, M., Durasiewicz, S., \& Lassenius, C. (2009). Using Scrum in Distributed Agile Development: A Multiple Case Study. 2009 Fourth IEEE International Conference on Global Software Engineering, 195-204.

[31] Peters, A., Hussain, W., Cajander, A., Clear, T., \& Daniels, M. (2015). Preparing the Global Software Engineer. International 


\section{GENERAL MANAGEMENT}

Conference on Global Software Engineering, 61-70.

[32] Poženel, M., \& Mahniè, V. (2016). Studying agile software estimation techniques: The design of an empirical study with students. Global Journal of Engineering Education, Vol. 18 No. 2, 53-58.

[33] Saldaña-ramos, J., Sanz-esteban, A., García, J., \& Amescua, A. (2014). Skills and abilities for working in a global software development team: a competence model. Journal of Software: Evolution and Process, Vol. 26 (February), 329-338.

[34] K. Schwaber, The professional scrum competencies (2017), www.scrum.org/ professional-scrum-competencies, Accessed 15 February 2020.

[35] Sievi-korte, O., Beecham, S., \& Richardson, I. (2018). Challenges and recommended practices for software architecting in global software development. Information and Software Technology, Vol. 106 (October), 234-253.

[36] Srivastava, P., \& Jain, S. (2017). A leadership framework for distributed self-organized scrum teams. Team Performance Management, Vol. 23 No. 5/6, 293-314.

[37] Tuffley, D. (2012). Optimising virtual team leadership in Global Software Development. IET Software, Vol. 6 No. 3, 176-184.

[38] Vallon, R., José, B., Prikladnicki, R., \& Grechenig, T. (2018). Systematic literature review on agile practices in global software development. Information and Software Technology, Vol. 96 (April), 161-180.

[39] Zahedi, M., \& Ali Babar, M. (2016). Why does site visit matter in global software development: A knowledge-based perspective. Information and Software Technology, Vol. 80, 36-56

[40] Zahedi, M., Shahin, M., \& Ali Babar, M. (2016). A Systematic Review of Knowledge Sharing Challenges and Practices in Global Software Development. International Journal of Information Management, Vol. 36 No. 6, 995-1019. 